\title{
The association of adenosine deaminase with coronary artery disease: Effect of gender and diabetes
}

\author{
Fulvia Gloria-Bottini ${ }^{1^{*}}$, Krzysztof Safranow ${ }^{2}$, Maria Banci ${ }^{3}$, Agnieszka Binczak-Kuleta $^{4}$, \\ Patrizia Saccucci ${ }^{1}$, Andrzej Ciechanowicz ${ }^{4}$, Andrea Magrini ${ }^{1}$, Zdzislawa Kornacewicz-Jach ${ }^{5}$, \\ Egidio Bottini ${ }^{1}$, Dariusz Chlubek ${ }^{2}$ \\ ${ }^{1}$ Department of Biomedicine and Prevention, School of Medicine, University of Rome Tor Vergata, Rome, Italy; \\ *Corresponding Author: gloria@med.uniroma2.it \\ ${ }^{2}$ Department of Biochemistry and Medical Chemistry, Pomeranian Medical University, Szczecin, Poland \\ ${ }^{3}$ Department of Cardiology, Valmontone Hospital, Valmontone, Italy \\ ${ }^{4}$ Department of Laboratory Diagnostics and Molecular Medicine, Pomeranian Medical University, Szczecin, Poland \\ ${ }^{5}$ Department of Cardiology, Pomeranian Medical University, Szczecin, Poland
}

Received 16 June 2012; revised 20 July 2012; accepted 1 August 2012

\begin{abstract}
An association between $\mathrm{ADA}_{1}$ and Coronary Artery Disease (CAD) has been observed in Polish and in Italian populations but in Italian population the association was present in males only. In order to enlighten these differences we have carried out a collaborative study in the two populations. In Italy 215 subjects admitted to the Hospital for CAD, 275 subjects with Type 2 Diabetes (T2D) without CAD and 398 healthy newborns were studied. In Poland 173 subjects with CAD and 200 healthy newborns were studied. Written informed consent was obtained from all subjects or from their mothers to participate to the study that was approved by the I.R.B. ADA polymorphism was determined by DNA analysis. Three way contingency table analysis was performed by a log linear model. The association between CAD and $A D A_{1}$ is present in non diabetic male subjects only: $O R=0.195, p=0.007$ in the Italian population and $O R=0.163, p=0.004$ in the Polish population. The data suggest a significant role of immunological mechanisms in the pathogenesis of CAD without diabetes. Gender differences in immune diseases could explain the lack of association in females.
\end{abstract}

Keywords: ADA; CAD; Gender; Diabetes

\section{INTRODUCTION}

An association between Adenosine Deaminase locus 1 $\left(\mathrm{ADA}_{1}\right)$ and Coronary Artery Disease $(\mathrm{CAD})$ has been described in the Polish population [1] and confirmed in the Italian population [2]. In Italy, however, a significant association was found in males only. In order to enlighten these differences we have carried out a collaborative study involving both populations.

$\mathrm{ADA}_{1}$ is a polymorphic enzyme present in all mammalian tissue that catalyzes the irreversible deamination of adenosine to inosine [3]. It is controlled by a locus with 2 codominant alleles $\mathrm{ADA}_{1} * 1$ and $\mathrm{ADA}_{1} * 2$ located in the long arm of chromosome 20 [4]: the activity associated to $\mathrm{ADA}_{1} * 2$ is lower than that associated to $\mathrm{ADA}_{1} * 1$.

Adenosine is an important local hormone regulating blood flow, neurotransmission, physiology of smooth muscle and platelet aggregation. In the liver adenosine counteracts insulin action by activating $\mathrm{A} 2 \mathrm{~B}$ receptors [5]. $\mathrm{ADA}_{1}$ and $\mathrm{CD} 26$ are colocalized on $\mathrm{T}$ cell surface and these cells are much more resistant to the inhibitory effects of adenosine.

Adenosine is a cardioprotective agent [6], thus reduced activity in $\mathrm{ADA}_{1} * 2$ allele carriers may have a beneficial effect on cardiac function. Moreover ecto$\mathrm{ADA}_{1}$ interacts with Adenosine receptor $\mathrm{A}_{1}$ [7] which plays an important role in ischaemic preconditioning [8]. Inhibition of platelet aggregation and adhesion and antiinflammatory properties of adenosine [9] may also play an important role in the susceptibility to CAD [10].

\section{MATERIAL AND METHODS}

The following samples were considered.

ITALY

215 subjects admitted to the hospital for CAD.

275 subjects with type 2 diabetes without CAD (as 
controls for CAD with T2D).

398 consecutive healthy newborns (as controls for CAD without diabetes).

\section{POLAND}

173 subjects admitted to the hospital for CAD.

200 consecutive healthy newborns (as controls for CAD without diabetes).

Subjects with type 2 diabetes without CAD were not available for this population.

Written informed consent was obtained from all subjects or from their mothers to participate to the study that was approved by the I.R.B.

Adenosine deaminase genotype determination was carried out as previously described [1]. Three way contingency table analysis was carried out by a log linear model according to Sokal and Rohlf [11].

\section{RESULTS}

Table 1 shows the distribution of $\mathrm{ADA}_{1}$ genotypes (phenotypes) in Coronary Artery Disease (Italy and Poland), in type 2 diabetes without CAD (Italy) and in healthy newborns (Italy and Poland) in relation to gender and Diabetes. The relationship among the variables considered i.e. $\mathrm{ADA}_{1}$ genotype, $\mathrm{CAD}$, diabetes, gender and population have been examined by log linear models.

The analysis of interaction among $\mathrm{ADA}_{1}$, diabetes and gender (a) within CAD subjects shows a significant interaction among the three variables with a pattern similar in Italian and Polish samples. The analysis suggests that the relationship between $\mathrm{ADA}_{1}$ and diabetes depends on gender.

The analysis of interaction among $\mathrm{ADA}_{1}, \mathrm{CAD}(\mathrm{CAD}$

Table 1. The effect of diabetes and gender on the association between $\mathrm{ADA}_{1}$ and $\mathrm{CAD}$.

\begin{tabular}{|c|c|c|c|c|c|c|c|c|c|c|c|}
\hline \multicolumn{12}{|c|}{ Proportion of $\mathrm{ADA}_{1} * 2$ allele carriers } \\
\hline \multirow{2}{*}{ Gender } & \multirow{2}{*}{ Diabetes } & \multicolumn{2}{|c|}{ CAD Italy } & \multicolumn{2}{|c|}{ CAD Poland } & \multicolumn{2}{|c|}{ T2D without CAD Italy } & \multicolumn{2}{|c|}{ Newborns Italy } & \multicolumn{2}{|c|}{ Newborns Poland } \\
\hline & & $\%$ & total $\mathrm{n}$ & $\%$ & total $n$ & $\%$ & total $\mathrm{n}$ & $\%$ & total $n$ & $\%$ & total $n$ \\
\hline \multirow{2}{*}{ Females } & Yes & $14.3 \%$ & 35 & $0.0 \%$ & 8 & $17.0 \%$ & 147 & & & & \\
\hline & No & $22.2 \%$ & 63 & $10.7 \%$ & 28 & & & $13.1 \%$ & 206 & $11.4 \%$ & 105 \\
\hline \multirow{2}{*}{ Males } & Yes & $15.6 \%$ & 45 & $11.1 \%$ & 36 & $20.2 \%$ & 128 & & & & \\
\hline & No & $4.2 \%$ & 72 & $3.0 \%$ & 101 & & & $18.2 \%$ & 192 & $15.8 \%$ & 95 \\
\hline
\end{tabular}

Statistical analyses: three way contingency table analysis by a log linear model.

\begin{tabular}{|c|c|c|c|c|c|c|}
\hline \multicolumn{7}{|c|}{$\frac{\text { (a) Interaction } \mathrm{ADA}_{1}}{\mathrm{x}=\text { Diabetes; } \mathrm{y}=\mathrm{AD}} \frac{\mathrm{AD}}{\mathrm{AA}_{1} ; \mathrm{z}=\text { Gender }}$} \\
\hline \multirow[t]{2}{*}{ Italy } & & & & Poland & & \\
\hline & G & $\mathrm{df}$ & $\mathrm{p}$ & G & df & $\mathrm{p}$ \\
\hline \multirow{6}{*}{$\begin{array}{l}\mathrm{x} y \mathrm{z} \text { interaction } \\
\text { cumulative probability } \\
\frac{\text { (b) Interaction } \mathrm{ADA}_{1}-\mathrm{C} A}{\mathrm{x}=\mathrm{ADA}_{1} ; \mathrm{y}=\mathrm{CAD} \text { vs I }}\end{array}$} & 5.086 & 1 & 0.028 & 3.580 & 1 & 0.065 \\
\hline & $\chi^{2}=12$ & $=4$, & & & & \\
\hline & (CAD & orns & in NON DIA & SUBJECTS & & \\
\hline & wborns; & ulat & Polish) & & & \\
\hline & Males & & & Females & & \\
\hline & G & df & $\mathrm{p}$ & G & $\mathrm{df}$ & $\mathrm{p}$ \\
\hline \multirow[t]{2}{*}{$\mathrm{x} \mathrm{y} \mathrm{z}$ interaction } & 0.039 & 1 & 0.650 & 0.891 & 1 & 0.350 \\
\hline & 20.651 & 2 & $\ll 0.0001$ & 2.903 & 2 & 0.260 \\
\hline \multicolumn{5}{|c|}{ after correction for multiple comparisons $\quad \mathrm{p}<0.001$} & & \\
\hline \multicolumn{7}{|c|}{ (c) Interaction $\mathrm{ADA}_{1}$-Gender-Population in CAD DIABETICS } \\
\hline \multicolumn{7}{|c|}{$\mathrm{x}=\mathrm{ADA}_{1} ; \mathrm{y}=$ Gender; $\mathrm{z}=$ Population (Italian vs Polish) } \\
\hline & G & df & $\mathrm{p}$ & & & \\
\hline $\mathrm{x} y \mathrm{z}$ interaction & 1.398 & 1 & 0.270 & & & \\
\hline $\mathrm{x} y$ independence & 1.717 & 2 & 0.450 & & & \\
\hline \multicolumn{7}{|c|}{ (d) Interaction $\mathrm{ADA}_{1}$-Gender-Population in CAD NON DIABETICS } \\
\hline \multicolumn{7}{|c|}{$\mathrm{x}=\mathrm{ADA}_{1} ; \mathrm{y}=$ Gender; $\mathrm{z}=$ Population (Italian vs Polish) } \\
\hline & G & df & $\mathrm{p}$ & & & \\
\hline $\mathrm{x} y \mathrm{z}$ interaction & 0.233 & 1 & 0.650 & & & \\
\hline $\mathrm{x} y$ independence & 12.985 & 2 & 0.002 & & & \\
\hline
\end{tabular}


vs newborns) and population (b) in non diabetic subjects shows a lack of interaction in both males and females suggesting that the relationship between $\mathrm{ADA}_{1}$ and $\mathrm{CAD}$ is similar in the two populations studied. The association between $\mathrm{ADA}_{1}$ and CAD is very strong in males $\chi^{2}=$ $20.651, \mathrm{df}=2, \mathrm{p} \ll 0.0001$, after correction for multiple comparison $\mathrm{p}<0.001$ ) but is lacking in females.

Since in the Polish population we had no data on diabetic subjects without CAD a similar analysis comparing CAD diabetics with non-CAD diabetics could not be performed.

The analysis of interaction among $\mathrm{ADA}_{1}$, gender and population in CAD diabetics (c) shows no significant association between $\mathrm{ADA}_{1}$ and gender in both Italian and Polish populations. On the contrary the same analysis in CAD non diabetics (d) shows a significant association between $\mathrm{ADA}_{1}$ and gender that shares a similar pattern in Italian and Polish populations.

From these analyses it can be safely concluded 1) that the association between $\mathrm{CAD}$ and $\mathrm{ADA}_{1}$ is present in non diabetic subjects only and 2) that the pattern of association in non diabetic CAD subjects depends on gender and it is present and very strong among males only: OR $\left(\mathrm{ADA}_{1} 2-1\right.$ vs $\mathrm{ADA}_{1} 1 / \mathrm{CAD}$ vs controls $)=0.195$; $95 \%$ C.I. $0.059-0.693(\mathrm{p}=0.007)$ in the Italian population and $\mathrm{OR}=0.163 ; 95 \%$ C.I. $0.047-0.630(\mathrm{p}=0.004)$ in the Polish population. For both populations combined O.R. $0.17095 \%$ C.I. $0.064-0.425(\mathrm{p}=0.00002)$.

\section{DISCUSSION}

Since a number of newborns will suffer CAD later in their life, it could be objected that these infants do not represent a reliable control for our study. However, assuming that a given genotype is more susceptible with respect to other genotypes to $\mathrm{CAD}$, the difference between cases and newborns would be lower as compared to the difference between cases and adults without CAD. Therefore taking newborns as controls the association of CAD with a given genotype will be underevaluated. If the association is statistically significant "newborns" can be considered a reliable control.

The present data collected in two independent White European populations show that the association between $\mathrm{CAD}$ and $\mathrm{ADA}_{1}$ is present in non diabetic patients only: moreover such association is present and very marked among males only. Considering both populations in males the proportion of genotypes carrying the $\mathrm{ADA}_{1} * 2$ allele is much lower among CAD patients than among controls.

The difference between males and females could be due to different early fatality rate; such difference, however, is present in non diabetic but not in diabetic subjects and this seems against such hypothesis. Unfortunately, we have no data on the subjects died during the early stages of cardiac attack.

The fact that association between CAD and $\mathrm{ADA}_{1}$ is present in non diabetic subjects only suggests the existence of different mechanisms leading to CAD. A role of immunological factors has been suggested for atherosclerosis: taking into account the well known role of $\mathrm{ADA}_{1}$ in immunological diseases, the association of $\mathrm{CAD}$ with $\mathrm{ADA}_{1}$ suggests a prevalent role of immunological factors in the pathogenesis of coronary artery atherosclerosis in $\mathrm{CAD}$ without diabetes. In CAD with diabetes a role of metabolic factors could be more important explaining the lack of association with $\mathrm{ADA}_{1}$ polymorphism.

Gender differences in immune diseases are well documented and it has been suggested that in association studies concerning immune diseases males and females should be examined separately [12]. Thus, assuming an immune component in the association between $\mathrm{ADA}_{1}$ and $\mathrm{CAD}$ the differences observed between males and females are in line with other studies. Hormonal factors may explain these differences. The immune mechanism, however, does not exclude a direct role of adenosine as a cardioprotective agent.

\section{REFERENCES}

[1] Safranow, K., Rzeuski, R., Binczak-Kuleta, A., Czyzycka, E., Skowronek, J., Jakubowska, K., et al. (2007) ADA*2 allele of the adenosine deaminase gene may protect against coronary artery disease. Cardiology, 108, 275-281. doi:10.1159/000099096

[2] Banci, M., Saccucci, P., D’Annibale, F., Dofcaci, A., Trionfera, G., Magrini, A., et al. (2009) Adenosine deaminase genetic polymorphism and coronary artery disease. Cardiology, 112, 74-75. doi:10.1159/000139954

[3] Spencer, N., Hopkinson, D. and Harris, H. (1968) Adenosin deaminase polymorphism in man. Annals of Human $\mathrm{Ge}$ netics, 32, 9-14. doi:10.1111/j.1469-1809.1968.tb00044.x

[4] Honing, J., Martiniuk, F., D’Eustachio, P., Zamfirescu, C., Desnick, R., Hirschhorn, K., et al. (1981) Confirmation of the regional localization of genes for human acid-glucosidase and adenosine deaminase by somatic cell hybridisation. Annals of Human Genetics, 48, 49-56. doi:10.1111/j.1469-1809.1984.tb00833.x

[5] Yasuda, N., Inoue, T., Horizoe, T., Nagata, K., Minami, H., Kawata, T., et al. (2003) Functional characterization of the adenosine receptor contributing to glycogenolysis and gluconeogenesis in rat hepatocytes. European Journal of Pharmacology, 459, 159-166. doi:10.1016/S0014-2999(02)02832-7

[6] Barankiewicz, J., Danks, A.M., Abushanab, E., Makings, L., Wiemann, T., Wallis, R.A., et al. (1997) Regulation of adenosine concentration and cytoprotective effects of novel reversible adenosine deaminase inhibitors. Journal of Pharmacology and Experimental Therapeutics, 283, 1230-1238.

[7] Ciruela, F., Saura, C., Canela, E.I., Mallol, J., Lluis, C. 
and Franco, R. (1996) Adenosine deaminase affects ligand-induced signalling by interacting with cell surface adenosine receptors. FEBS Letters, 380, 219-223. doi:10.1016/0014-5793(96)00023-3

[8] Heusch, G. and Schulz, R. (1997) Endogenous protective mechanisms in myocardial ischemia: Hibernation and ischaemic preconditioning. American Journal of Cardiology, 80, 26A-33A. doi:10.1016/S0002-9149(97)00455-4

[9] Jackson, E.K., Koehler, M., Mi, Z., Dubey, R.K., Tofovic, S.P., Carcillo, J.A., et al. (1996) Possible role of adenosine deaminase in vaso-occlusive diseases. Journal of $\mathrm{Hy}$ pertension, 14, 9-29. doi:10.1097/00004872-199601000-00003

[10] McCallion, K., Harkin, D.W. and Gardiner, K.R. (2004) Role of adenosine in immunomodulation: Review of the literature. Critical Care Medicine, 32, 273-277. doi:10.1097/01.CCM.0000098026.12020.45

[11] Sokal, R.R. and Rohlf, F.J. (1981) Biometry. Freeman, New York.

[12] Whitacre, C.C., Reingold, S.C. and O'Looney, P.A. (1999) A gender gap in autoimmunity. Science, 283, 1277-1278. doi:10.1126/science.283.5406.1277 